\title{
Genetic variability in residual feed intake in rainbow trout clones and testing of indirect selection criteria (Open Access publication)
}

\author{
Laure Grima $^{1,2 *}$, Edwige Quillet ${ }^{1}$, Thierry Boujard ${ }^{1}$, \\ Christèle Robert-GraniÉ ${ }^{3}$, Béatrice Chatain ${ }^{2}$, Muriel MambrinI ${ }^{1}$ \\ ${ }^{1}$ INRA, UR 544 Génétique des poissons, Domaine de Vilvert, 78350 Jouy-en-Josas, France \\ ${ }^{2}$ Ifremer, Station d'aquaculture expérimentale, chemin de Maguelone, \\ 34250 Palavas-les-Flots, France \\ ${ }^{3}$ INRA, UR 631 Station d'amélioration génétique des animaux, BP 52627, \\ 31320 Castanet-Tolosan, France
}

(Received 10 January 2008; accepted 1st July 2008)

\begin{abstract}
Little is known about the genetic basis of residual feed intake (RFI) variation in fish, since this trait is highly sensitive to environmental influences, and feed intake of individuals is difficult to measure accurately. The purpose of this work was (i) to assess the genetic variability of RFI estimated by an X-ray technique and (ii) to develop predictive criteria for RFI. Two predictive criteria were tested: loss of body weight during feed deprivation and compensatory growth during re-feeding. Ten heterozygous rainbow trout clones were used. Individual intake and body weight were measured three times at threeweek intervals. Then, individual body weight was recorded after two cycles of a three-week feed deprivation followed by a three-week re-feeding. The ratio of the genetic variance to the phenotypic variance was found high to moderate for growth, feed intake, and RFI ( $V G$ / $V P=0.63 \pm 0.11,0.29 \pm 0.11,0.29 \pm 0.09$, respectively). The index that integrates performances achieved during deprivation and re-feeding periods explained $59 \%$ of RFI variations. These results provide a basis for further studies on the origin of RFI differences and show that indirect criteria are good candidates for future selective breeding programs.
\end{abstract}

rainbow trout / clone / residual feed intake / indirect criteria / selection

\section{INTRODUCTION}

In farmed animals, food represents at least $50 \%$ of the production costs. Therefore, improvement of feed efficiency (the ratio of wet mass gain to feed intake) is an important target for cost reduction. In addition, feed efficiency enhancement

*Corresponding author: laure.grima@jouy.inra.fr 
would lead to a reduction in environmental loading, particularly in the case of activities such as fish farming where effluents can directly impact environment. Among the possible means of improving feed efficiency, selective breeding is considered a promising method. Cultured fish populations are likely to have a high genetic potential for improvement through breeding, since most of the species reared today have been only recently domesticated. Selection for growth using family or individual selection in fish can lead to a $10-20 \%$ gain in body weight per generation [6,12], which is a far greater level of progress than that achieved in endothermic terrestrial vertebrates. In salmonids, the main correlated response to selection for growth is increased feed intake capacity $[27,38,39]$, which is probably due to the high correlation between these two traits $[30,35]$. However, the effect of growth selection on feed efficiency is disputed. While Kause et al. [21] have found that rapid growth in rainbow trout (Oncorhynchus mykiss) is related to high feed efficiency, Mambrini et al. [27] have not detected any improvement in feed efficiency when selecting brown trout (Salmo trutta) for growth gain. Hence at least in brown trout, selection on growth does not necessarily lead to improvement in feed efficiency. Thus, a specific strategy is needed to develop effective selection programs for feed efficiency in fish.

In endothermic land vertebrates, residual feed intake (RFI) is generally used to study the determinants of feed efficiency. Calculation of RFI uses a model to predict expected consumption. The difference between actual consumption and expected consumption of an individual over a given weight gain interval is calculated to give a residual, i.e. RFI, for each animal tested. RFI is thought to be a better measurement than feed efficiency itself, mainly because it is not a ratio. If a ratio is used, it is not possible to distinguish whether any improvement in feed efficiency results from a decrease in feed intake, from an increase in weight gain or from a modification of both variables. Moreover, the ratio confounds the variability of intake and gain, both of which are highly sensitive to environmental variation [13]. In cattle, pigs, sheep, and chickens, the heritability of RFI lies between 0.2 and 0.4 , and the genetic correlation with feed efficiency is moderate to high $(-0.23$ to -0.66$)[9,17,37,41]$. In chickens, selection on RFI has clearly resulted in significant improvement of feed efficiency [4]. In fish, no selection program on feed efficiency or RFI has yet been put into action, and little is known about the genetic components of these traits. The major reasons are the difficulties encountered to measure feed intake and the variability of these two traits. Indeed, since fish are generally reared in large groups in tanks, it is difficult to obtain accurate measurements of the individual intake and this explains why the literature on this subject is rare in fish compared with other species.

The first estimation of genetic parameters for feed efficiency was obtained for rainbow trout reared in individual aquaria, and feed intake was indirectly 
estimated from oxygen consumption [22]. Under such conditions, feed efficiency showed no substantial genetic component (heritability $3 \pm 10 \%$; [22]). In this study, measurement of feed intake was very imprecise, which may have masked important effects. In another study, in which feed distribution and waste were accurately measured in Atlantic salmon reared in separate family tanks [14], inter-family variations in feed efficiency were detected $[23,40]$. However, this family effect may have been overestimated because within-family variance could not be estimated. In a recent study involving six different strains of rainbow trout reared in individual aquaria, voluntary intake was measured by accurate visual observation of the pellets ingested by each fish. RFI was calculated as the difference between the intake observed and the intake predicted from a bioenergetic model [36]. The differences between cross-types indicated a significant genetic component for RFI [36]. The accuracy of the estimations obtained with this strategy may be impaired by the fact that social interactions were not considered, even though they can be a major cause of individual variation [19]. It has been shown that feed intake of an individual fish within a group can be estimated from X-ray images of fish supplied with food containing a suitable dense marker $[5,18,29]$. The weakness of this approach is the low repeatability of estimated feed intake (from 0.09 to 0.32 in rainbow trout): a minimum of three repeated records seems to be necessary in order to buffer day-to-day variation and accurately describe the intake versus gain relationship [20]. However, even with five measurements, estimates of feed efficiency heritability remain low $(6 \pm 10 \%)[33]$.

In fish, the difficulties of measuring individual RFI performances have prevented accurate estimations of individual genetic values. Therefore, selection schemes directly targeting RFI, like those commonly used in land vertebrates, represent a challenge in fish. Predictive criteria for RFI would be precious tools for fish breeding programs, which could use these indirect criteria to design alternative selection strategies.

The objectives of the present study were (i) to assess the genetic variability of RFI using the X-ray technique to estimate individual feed intake and fish clones to multiply measurements per genotype and (ii) to explore the relative merits of potential indirect criteria for predicting RFI: weight loss during feed deprivation and weight gain during re-feeding.

Isogenic clonal lines have been successfully developed in rainbow trout by chromosome set manipulation methods using gynogenesis techniques $[10,24,32]$. Clones are individuals that are strictly genetically identical, and thus genetic variability within a clone is null. Clones are an excellent tool to study the genetic variability of traits, such as RFI, which are highly sensitive to environmental variation. Indeed, the use of clones makes it possible to increase 
the number of measurements per genotype and hence to improve the accuracy of mean genotype value estimation.

Among the various indirect criteria to test, we chose to explore traits likely to reflect variations in maintenance requirements and metabolic efficiency, because in land vertebrates several studies have demonstrated that these capacities are significantly correlated with RFI genetic variations [16]. In addition, it was necessary to carry out measurements that were noninvasive and easy to record in rearing conditions. Two traits were chosen for assessment: loss of body weight during a period of feed deprivation and subsequent gain in body weight after a re-feeding period. Loss of weight during feed deprivation was chosen because it is assumed to be proportional to the maintenance requirement $[8,25]$. Compensatory growth was chosen because it has been shown to be associated with variations in RFI [26]. Moreover, we assume that these two traits reflect protein turnover rate.

The validity of these indirect criteria was analyzed through between clone variations in RFI and between clone correlations of RFI with body weight loss and gain during successive periods of feed deprivation and re-feeding.

\section{MATERIALS AND METHODS}

\subsection{Experimental animal production and management}

Ten heterozygous clones of rainbow trout (Oncorhynchus mykiss) were obtained by mating females and males from different homozygous clonal lines, developed at the Gournay-sur-Aronde INRA fish farm [32]. To avoid maternal effects further differentiating the clones, all the females used belonged to a single clone. We chose male breeders (XX sex reversed females) that were not related to the female clone used. The ova of seven females were pooled and then divided into 10 batches. Each batch was fertilized with the milt of a single male. All fertilizations were performed on the same day. The homozygous status of each breeder was checked using four and nine microsatellite markers for the dams and sires, respectively.

The 10 progenies were incubated separately in the hatchery of the Gournay-surAronde INRA fish farm. After hatching, each clone was reared in two tanks (approximately 850 fish per tank, $50 \mathrm{~L}$ flow-through tanks). Fish were fed a commercial pelleted feed, provided in excess by automatic feeders ( $12 \mathrm{~h}$ per day) until the beginning of the experiment. The experiment started when the fish reached a mean body weight of $7.5 \mathrm{~g}$ (182 days post fertilization: $\mathrm{dpf}$ ). Forty-two fish of each clone were randomly and equally picked from the two tanks and split among six tanks of $50 \mathrm{~L}$ in a balanced factorial design (seven fish per clone per tank, 70 fish per tank). All fish were individually weighed and tagged (PIT-Tag®). 
Then, they underwent two successive experimental phases: the first (from 255 to $298 \mathrm{dpf}$ ) aimed at detecting genetic variability for RFI, the second (from 317 to $443 \mathrm{dpf}$ ) aimed at testing the relevance of the indirect criteria.

The water temperature followed the seasonal variations in the river supplying the farm, ranging from 7 to $16{ }^{\circ} \mathrm{C}$ during the experiments. Mortality was recorded throughout the entire experimental period.

\subsection{Recorded traits}

During the first experimental phase, the amount of food eaten by each fish during a "one-day meal" (corresponding to the 4-h daily feeding) was measured at three time points at three-week intervals. Individual body weight gain (BWG) was also recorded over the whole period. The cumulative individual intake (CI) over the first phase was then calculated, and the residual feed intake (RFI) estimated from the relationship between BWG and CI. During the second experimental phase, the body weight after five weeks of growth, loss of body weight after a three-week feed deprivation period $\left(G_{f d}\right)$, and body weight after a three-week re-feeding period $\left(G_{r f}\right)$ were recorded (over two cycles for feed deprivation and re-feeding). Fish were fed a commercial pelleted feed (Skretting $48 \%$ protein and $24 \%$ lipid according to the manufacturer) with an automatic feeder, in slight excess of the usual daily ration.

\subsubsection{First experimental phase: recording of residual feed intake}

The individual feed intake during a one-day meal was measured using an $\mathrm{X}$-ray technique [28] and fulfilling the prerequisites described in [18]. This implied that (i) the length of time between the moment feeding began and the X-ray did not exceed the digestion time, i.e. no feed came out of the stomach and (ii) the time interval between two successive estimates was sufficient to allow complete evacuation of the markers from the gut.

This experiment lasted 43 days, during which one-day meal intake was measured three times: at 255, 277, and 298 dpf. Feed distribution lasted four hours per day during the whole experimental phase. To ensure an identical delay between the end of the feeding period and the X-rays for all the tanks, the first feeding times among tanks were set at regular one-hour intervals. On the days when estimates were made, fish were fed as usual but the commercial feed was replaced by a labelled diet containing $1 \%$ lead glass ballotini beads (Sillibeads type H, 450-600 $\mu \mathrm{m}$, DLO Equipment, Belgium). These beads were mixed into ground feed, which was then re-pelleted. Half an hour after the end of the feed distribution, the fish were anesthetized (2-phenoxy-ethanol 
$0.4 \mathrm{~mL} \cdot \mathrm{L}^{-1}$ ), individually identified using a PIT-Tag reader (PRD-60, Réseaumatique, Conches, France or www.reseaumatique.fr), weighed to the nearest $0.1 \mathrm{~g}$, and X-rayed (TR 80/20 portable X-ray, Todd Research, UK, $80 \mathrm{~V}-20 \mathrm{~A}, 1 \mathrm{~s}$ exposure). Ballotini beads present in the stomach were then counted visually on the radiographs. Individual one-day meal feed intake was calculated from a reference calibration curve developed from previously known weights of labelled feed and their ballotini content $\left(N=19 ; R^{2}=0.99\right)$.

The following variables were calculated:

- $\quad$ CI $(\mathrm{g})=$ mean one-day meal intake $\times 43$ days

where the mean one-day meal intake is the mean of the feed intakes recorded at 255,277 , and 298 dpf.

- $\quad$ BWG (g) = final body weight - initial body weight

where the final body weight (BW) is the BW at $298 \mathrm{dpf}$ and initial BW is the BW at $255 \mathrm{dpf}$.

The determination coefficient of the regression line of CI on BWG, estimated from all the individual data, was significantly different from $0\left(R^{2}=0.22\right.$; $P<0.001)$. The regression equation was used to predict individual feed intake and RFI was calculated for a given fish as the difference between the measured and predicted feed intake. Contrary to what is commonly performed in land vertebrates, the RFI equation did not include the metabolic body weight. Indeed, the use of metabolic body weight appeared unnecessary because of the isometric shape of the current regression.

\subsubsection{Second experimental phase: testing potential indirect criteria}

After a five-week growth period (g; from day 317 to day 353), fish were submitted to a three-week period of feed deprivation ( $f d l$; from day 353 to day 373), immediately followed by a four-week period of re-feeding ( $r f 1$; from day 374 to day 401) during which they were fed ad libitum as during the basic growth period. Then, a second round of a three-week feed deprivation ( $f d 2$; from day 402 to day 423) and a three-week re-feeding ( $r f 2$; from day 424 to day 444) was applied. We called the first five-week growth period, basic growth, to avoid confusion between this period and the compensatory growth.

Fish were individually weighed at the beginning and at the end of each period of feed deprivation or re-feeding and the thermal growth coefficient $(G)$ was calculated. This variable corrects for the effects of the initial body weight. 
Assuming that the influence of temperature of growth is linear, this variable also corrects for the effects of the temperature [7].

- Thermal growth coefficient $(G)=\frac{\left(W_{f}^{1 / 3}-W_{i}^{1 / 3}\right)}{\sum T}$

where $W_{f}$ and $W_{i}$ are the body weights at the end and beginning, respectively, of the considered period, and $\sum T$ is the sum of temperatures during this period. Growth rates will be referred to as $G_{g}, G_{f d 1}, G_{r f 1}, G_{f d 2}$, and $G_{r f 2}$.

\subsection{Statistical analyses}

\subsubsection{Data set}

ANOVA and ANCOVA, multiple linear regression, and correlations were performed using the GLM, REG, and CORR procedures of SAS $\left.{ }^{(}\right)$SAS ${ }^{\circledR}$ Inst., Inc., Cary, NC), respectively. We checked the assumption of residual homoscedacity, as well as the independence of the variance from the mean. Variance components and clone genetic values were estimated using Asreml [11].

RFI analyses were performed on 365 fish only instead of the 420 because data on one of the three intake measurements were unavailable for 55 individuals. The reason is that these fish had moved on the X-radiographic plate making it impossible to count the number of ballotini beads in their stomach.

Analyses were made on all six tanks for the first experimental phase, but only on five tanks for the second experimental phase because of heavy mortality in one tank due to technical reasons.

\subsubsection{Validation of $X$-ray measurements}

To test if the feed intake measurements recorded with the X-ray technique were stable through time, we estimated phenotypic correlations between two feed intake records using all individual data. We also calculated the repeatability of the intake measurements as described in [20], where the repeatability, $r=1-V_{E S} /\left(V_{E S}+V_{E g}\right), V_{E s}$ being the within-individual variance arising from repeated measurements and $V_{E g}$ the between individual variance, the standard error was calculated as described by Becker [2].

\subsubsection{Between clone variation}

The clone effect was tested on all recorded traits (BW, CI, RFI, and growth rate, $G$ ) using the following analysis of variance model:

$$
-Y_{i j k}=\mu+\text { clone }_{i}+\operatorname{tank}_{j}+\text { clone }_{i} * \operatorname{tank}_{j}+e_{i j k}
$$


where $Y_{i j k}$ is an individual fish, $\mu$ is the estimated mean of the population, clone $e_{i}$ is the random clone effect, $\operatorname{tank}_{j}$ is the random tank effect, clone $_{i} * \operatorname{tank}_{j}$ is the interaction between the clone and tank effect, and $e_{i j k}$ the residual. Clone genetic values of BW, CI, RFI, and $G$ were obtained as solutions from the best linear unbiased prediction analysis using the Asreml software. When using Asreml, BW, CI, and RFI were tested separately, while the $G$ was tested in a multi-trait analysis to take into account the fact that the $G$ were calculated using repeated body weight measurements from the same fish. All the fish originating from the same clone were included as replicates of the same animal. The genetic and phenotypic components of CI, RFI, and indirect criteria were assessed with Asreml, using a model including clone as random effect and tank as fixed effect. For each trait, the genetic component of CI, RFI, and indirect criteria variability was calculated by dividing the genetic variance by the phenotypic variance $(V G / V P)$. The genetic component obtained included both additive and dominance effects, this latter effect could not be estimated because of the experimental breeding design, which only used one dam.

\subsubsection{Between clone correlations}

The correlation between indirect criteria and RFI was assessed to determine whether they would make suitable predictive criteria. All correlations were calculated using the clone's genetic value obtained with the Asreml software. Indirect criteria were tested separately and in combination (i.e. composite criteria). $G_{f d 1}$ and $G_{f d 2}$ genetic values were combined like the genetic values of $G_{r f 1}$ and $G_{r f 2}$ to test whether the use of both periods improved the prediction of RFI for weight loss during feed deprivation and for compensatory growth. In addition, $G_{f d l}$ and $G_{r f 1}$ genetic values were combined, like the genetic values of $G_{f d 2}$ and $G_{r f 2}$, to test: (i) whether one period of feed deprivation/re-feeding was more predictive than the other and (ii) whether for each period the use of both criteria improved the prediction of RFI. Finally all the $G$ criteria were summed to estimate the degree of prediction achieved when all periods were taken into account. To improve the degree of prediction of all the composite indirect criteria (i.e. $G_{f d 1}+G_{r f 1}, G_{f d 2}+G_{r f 2}$, $G_{f d 1}+G_{f d 2}, G_{r f 1}+G_{r f 2}$, and $G_{f d 1}+G_{r f 1}+G_{f d 2}+G_{r f 2}$ ), weighting coefficients were assigned to the $G$ genetic values. These weighting coefficients were estimated by performing multiple linear regression of all the $G$ on RFI, using the method of maximum R-square improvement. Clone genetic values were used to perform the multiple linear regressions. Correlations between RFI and weighted indirect criteria were then calculated. Genetic and phenotypic components of the weighted indirect criteria were estimated using the same analyses as those used for the other predictive criteria. 


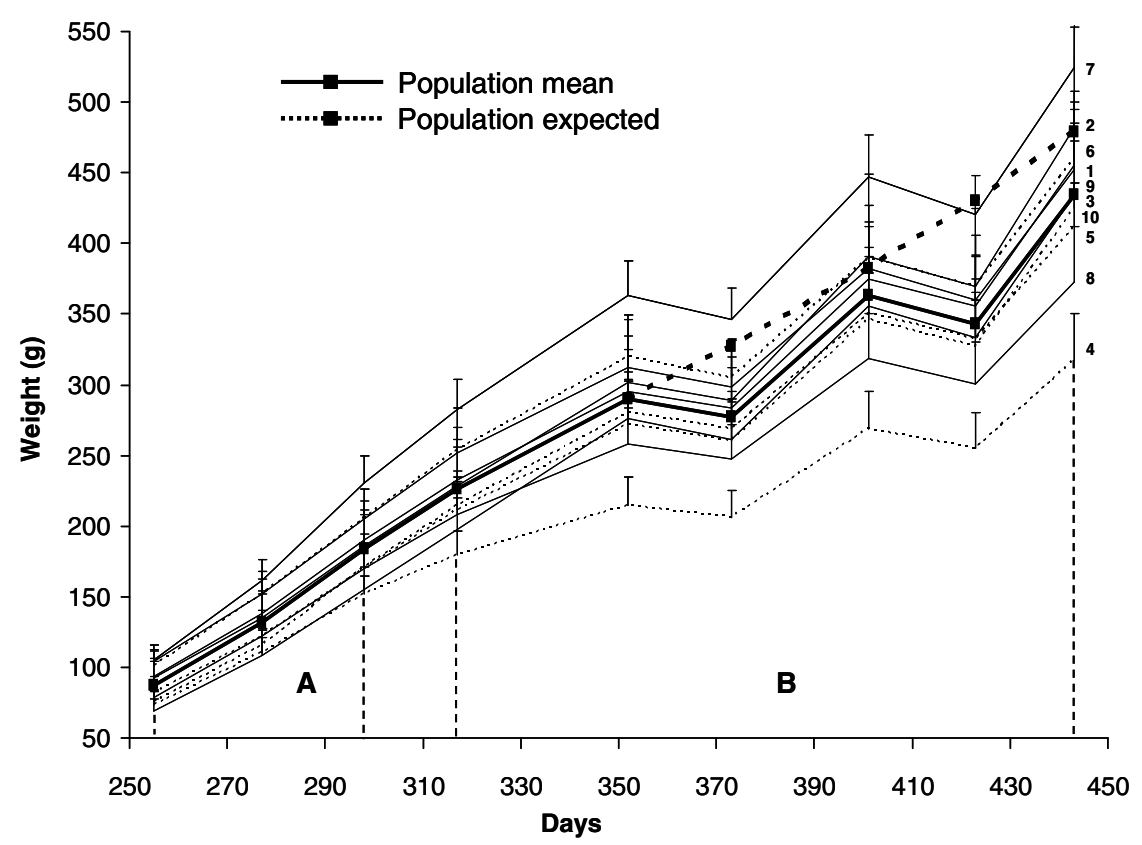

Figure 1. Mean body weight ( $\mathrm{g} \pm$ standard error) of 10 rainbow trout clones (1-10) fed ad libitum then submitted to two periods of feed deprivation each followed by periods of re-feeding. The bold line represents the population mean body weight. The dotted line represents the expected population mean body weight if fish are not submitted to feed deprivation. 'A' corresponds to the first experimental period, i.e. when the genetic variability of residual feed intake is estimated. ' $B$ ' corresponds to the second experimental period, i.e. when the indirect criteria are tested.

Table I. Phenotypic correlation coefficients $(R)$ between the different one-day meal feed intakes (FI) from 10 rainbow trout clones. Exponents indicate the age of the fish when traits were recorded.

\begin{tabular}{lcc}
\hline & $R$ & $P_{\text {value }}$ \\
\hline $\mathrm{FI}^{255-277}$ & 0.079 & 0.125 \\
$\mathrm{FI}^{277-298}$ & 0.184 & $<0.001$ \\
$\mathrm{FI}^{255-298}$ & 0.257 & $<0.001$ \\
\hline
\end{tabular}

$P_{\text {value }}=$ probability that correlation differs from zero; $N=365$.

Stability through time of the potential indirect criteria was tested by calculating correlations between a clone's genetic values in the two periods of feed deprivation and the two periods of re-feeding. 


\section{RESULTS}

At the end of the experiment and in the five survival tanks, survival percentages ranged between 98 and 100\% depending on tank with no clone effect. Clones exhibited different growth capacities during the first experimental phase and different compensatory growth capacities after feed deprivation during the second phase (Fig. 1).

The repeatability of the one-day meal feed intake was low $0.13 \pm 0.06$, as well as the phenotypic correlations between the different one-day meal feed intakes (Tab. I), underlining the need for repeated measurements. Nevertheless, correlations were significant, except between the first and the second records.

\subsection{Between clone variability for residual feed intake}

Significant clone and tank effects were found for BW and FI on each experimental day (Tab. II), with between clone variation representing $63 \%$ of the phenotypic variance of the initial BW (Tab. III). Significant differences between clones and between tanks were also found for the CI, and BWG (Tab. II), between clone variation representing $29 \%$ of the phenotypic CI variance. Substantial between clone variations were found for RFI as well (Tab. II). Since the interaction between clone and tank effects was very close to significance, we performed a likelihood ratio test on this interaction with PROC MIXED. The results showed that we could not reject the null hypothesis (absence of significant interactions). The model taking into account the interaction between clone and tank effects showed a strong clone effect on RFI (Tab. II). Therefore, when for a $100 \mathrm{~g}$ weight gain, the mean CI of the populations was $105 \mathrm{~g}$, the RFI varied between $-11.1 \mathrm{~g}$ for the most efficient clone and $26.6 \mathrm{~g}$ for the least efficient clone. Between clone variations in RFI represented $23 \%$ of the total phenotypic variation (Tab. III). A positive genetic correlation was found between the RFI and CI $(R=0.755 ; P=0.012)$, which indicates that the fish eating most had the lowest RFI.

\subsection{Validity of indirect criteria}

No mortality was recorded during the second experimental phase (i.e. $100 \%$ survival), indicating that fish overcame the feed deprivation and re-feeding without any major problem. During feed deprivation, fish weight loss was on average 4.38 and $5.44 \%$ during the first and second challenges, respectively (clone means of $G$ were -0.050 and -0.065 during the first and second feed deprivation periods, respectively). Fish growth rate $G$, which was 0.136 during 
Table II. Mean values and $F$ test values of clone, tank, and clone*tank effects on body weight (BW), one-day meal feed intake (FI), body weight gain (BWG), cumulative feed intake $(\mathrm{CI})$, and residual feed intake (RFI) from 10 rainbow trout clones. Exponents indicate the age of the fish when traits were recorded.

\begin{tabular}{lccclccccc}
\hline & $\mathrm{BW}^{255}$ & $\mathrm{BW}^{277}$ & $\mathrm{BW}^{298}$ & $\mathrm{FI}^{255}$ & $\mathrm{FI}^{277}$ & $\mathrm{FI}^{298}$ & $\mathrm{BWG}^{\mathrm{a}}$ & $\mathrm{Cl}^{\mathrm{a}}$ & $\mathrm{RFI}^{\mathrm{a}}$ \\
\hline Mean $(\mathrm{g})$ & 88.2 & 132.7 & 184.6 & 1.55 & 1.51 & 2.03 & 96.4 & 71.42 & 0 \\
$F_{\text {clone }}$ & $105.7^{* * * *}$ & $104.5^{* * *}$ & $111.8^{* * * *}$ & $5.29^{* *}$ & $6.1^{* * * *}$ & $14.8^{* * *}$ & $86.1^{* * *}$ & $15.0^{* * *}$ & $11.2^{* * *}$ \\
$F_{\text {tank }}$ & $17.1^{* * * *}$ & $22.4^{* * *}$ & $16.0^{* * *}$ & 2.09 & $11.6^{* * *}$ & $17.2^{* * *}$ & $10.14^{* * *}$ & $11.1^{* * * *}$ & $11.7^{* * *}$ \\
$F_{\text {clone }{ }^{*} \text { tank }}$ & 1.08 & 1.14 & 1.07 & $1.42^{*}$ & $1.48^{*}$ & $1.72^{* *}$ & 1.25 & $1.65^{* *}$ & $1.58^{*}$ \\
\hline
\end{tabular}

a $255-298 ; * P<0.05 ; * * P<0.01 ; * * * P<0.001 ; N=365$.

Table III. Genetic components of variability measured from 10 rainbow trout clones ( $V G / V P$, where $V G$ is the genetic variance, and $V P$ the phenotypic variance), given with the respective standard errors $( \pm$ S.E.) in: body weight at the beginning of the experiment $\left(B W^{255}\right)$, cumulative intake $(\mathrm{CI})$, residual feed intake (RFI), and indirect criteria: $G_{g}, G_{f d 1}, G_{r f 1}, G_{f d 2}$, and $G_{r f 2}$ (growth rates at different periods $g=$ basic growth, $f d l=$ first three-week feed deprivation, $r f l=$ first three-week re-feeding, $f d 2=$ second three-week feed deprivation, $r f 2=$ second three-week re-feeding).

\begin{tabular}{lcc}
\hline & $V G / V P$ & \pm S.E. \\
\hline$B W^{255}$ & 0.63 & 0.11 \\
CI & 0.29 & 0.11 \\
RFI & 0.23 & 0.09 \\
$G_{g}$ & 0.69 & 0.10 \\
$G_{f d 1}$ & 0.43 & 0.12 \\
$G_{r f 1}$ & 0.46 & 0.12 \\
$G_{f d 2}$ & 0.32 & 0.11 \\
$G_{r f 2}$ & 0.51 & 0.12 \\
\hline
\end{tabular}

${ }^{\mathrm{a}} N=365$.

the initial growing phase, increased by 1.8 to 2.1 times during re-feeding (clone means of $G$ were 0.245 and 0.292 during the first and second re-feeding periods, respectively). A strong correlation was found between the genetic values $G_{f d l}$ and $G_{f d 2}$, measured in the first and the second periods of feed deprivation $(R=0.93 ; P<0.001)$, and between $G r_{f 1}$ and $G r_{f 2}(R=0.95 ; P<0.001)$.

Genetic components of variability for weight loss during feed deprivation and compensatory growth were significantly different from 0 (between 0.32 and 0.51 , Tab. III). 
Table IV. Coefficients of determination $\left(R^{2}\right)$ between genetic values of indirect criteria and residual feed intake from 10 rainbow trout clones for $G_{g}, G_{f d 1}, G_{r f 1}, G_{f d 2}$, and $G_{r f 2}$ (growth rates at different periods $g=$ basic growth, $f d l=$ first three-week feed deprivation, $r f 1=$ first three-week re-feeding, $f d 2=$ second three-week feed deprivation, $r f 2=$ second three-week re-feeding) and composite criteria ( $a, b, c, d, e)$, corrected by weighting coefficients.

\begin{tabular}{lcr}
\hline Indirect Criteria & $R^{2 \mathrm{f}}$ & $P_{\text {value }}$ \\
\hline$G_{g}$ & 0.02 & 0.73 \\
$G_{f d 1}$ & 0.07 & 0.46 \\
$G_{r f 1}$ & 0.21 & 0.19 \\
$G_{f d 2}$ & 0.01 & 0.74 \\
$G_{r f 2}$ & 0.22 & 0.17 \\
$G_{f d 1}-0.85 \cdot G_{f d d} \mathrm{c}$ & 0.20 & 0.19 \\
$G_{r f 1}+5.68 \cdot G_{r f 2}$ & 0.22 & 0.17 \\
$G_{f d 1}+0.36 \cdot G_{r f 1} \mathrm{a}$ & 0.53 & 0.02 \\
$G_{f d 2}+0.29 \cdot G_{r f 2} \mathrm{~b}$ & 0.44 & 0.04 \\
$G_{f d 1}+0.07 \cdot G_{r f 1}-0.44 \cdot G_{f d 2}+0.10 \cdot G_{r f 2} \mathrm{e}$ & 0.59 & $<0.01$ \\
\hline
\end{tabular}

$P_{\text {value }}=$ probability that the correlation differs from zero; ${ }^{\mathrm{f}} N=10$.

Whether they were taken separately or in combination, $G$ were not significantly correlated with RFI either during feed deprivation or during re-feeding (Tab. IV). Nevertheless, combining both periods of feed deprivation markedly improved the proportion of predicted RFI variations. Moreover, re-feeding periods seemed to be better correlated with RFI than were feed deprivation periods. For both the first and second periods, the integration and weighting of $G_{f d}$ and $G_{r f}$ improved the proportion of explained RFI variation. The first period explained RFI variation slightly better than the second one. The best predictive criterion was obtained when all the $G$ genetic values were combined in a single index (Fig. 2). Weighting coefficients of $G_{f d}$ were larger in absolute value than those of the $G_{r f}$, probably because weight loss during feed deprivation was proportionally lower than weight gain during re-feeding.

Finally, it is important to note that the basic growth $G_{g}$ (i.e. the growth period recorded after the characterization of RFI) is not correlated with RFI.

\section{DISCUSSION}

The present study demonstrates substantial genetic-based variation of RFI in rainbow trout. The use of clones has made it possible to buffer environmental and/or methodological variations in the trait, such as those arising from 


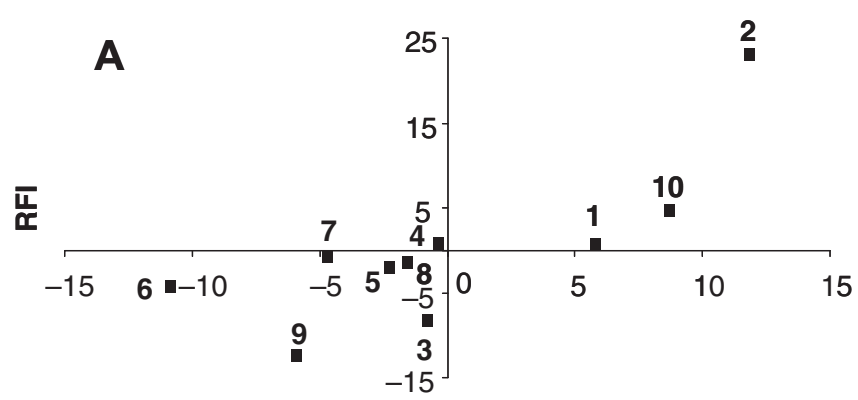

Weighting criteria

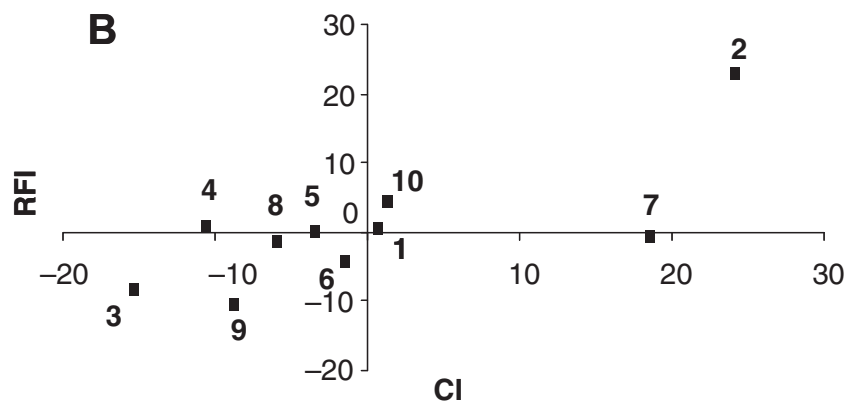

Figure 2. Correlations, for 10 rainbow trout clones $(1-10)$, between residual feed intake (RFI) and different indirect criteria: $\mathrm{A}=$ weighted criteria; $\mathrm{B}=$ cumulative feed intake (CI). Weighted indirect criteria correspond to the sum of all types of $G$ (growth rates) corrected by the weighting coefficients (see Tab. IV). Each square represents a clone.

day-to-day discrepancies in feed intake measured with the X-ray technique. We found a positive relationship between RFI and feed intake (Fig. 2), which is in line with the negative phenotypic correlation generally found between feed efficiency and feed intake [35]. RFI did not co-vary with initial body weight (data not shown), thus guaranteeing that RFI differences measured between clones are not due to initial differences in body weight (which would have implied variable maintenance costs [25]). Moreover in the present study, no correlation between RFI and growth was observed, indicating that, in rainbow trout, high growth is not strongly correlated with elevated RFI. All together these results suggest that genetic variability exists for metabolic efficiency.

Overall, we have estimated that the genetic variation of RFI explains $23 \%$ of the total phenotypic variation and is significantly different from 0 . This result is not surprising since genetic variability for feed efficiency is commonly observed in endothermic terrestrial vertebrates [31]. However, because of the genetic 
structure of our population (genetically identical fish and a single dam common to all individuals), this value cannot be compared with data found in the literature. Few studies have assessed genetic variability of feed efficiency in fish $[15,21,23,33,36,39]$. Among these only one study gives precise differences in RFI among families and individuals [35]. In this study, inter-individual RFI variations were measured on 40 fish held individually; fish body weight varied between 100 and $200 \mathrm{~g}$ and the RFI ranged between -0.77 and $0.76 \mathrm{~g}$ per day. However, these individual variations were confounded with possible tank effects. The use of individual tanks also prevented taking into account any effect from social interactions. From 70 families of European whitefish (Coregonus lavaretus) and using the X-ray technique to record individual feed intake, Quinton et al. were able to estimate genetic components of feed efficiency from fish held in a common tank [33]. The level of phenotypic variation explained by genetic variations in this study was low $(0.06 \pm 0.10)$, which does not agree with our results. This may be due to differences in family structure between the two studies. Indeed, in our study, for each trait recorded, the use of clones enabled us to characterize precisely genotype performances and therefore to emphasize the genetic component of phenotypic variations. This assumption is corroborated by the fact that for traits easy to measure, such as body weight gain, we estimated that the genetic variation explained $63 \%$ of the total phenotypic variation, while Quinton et al. estimated that the genetic variation explained $26 \%$ of the total phenotypic variation.

We have also validated that weight loss after a three-week feed deprivation and weight gain after a three-week period of re-feeding are suitable indirect criteria for the genetic improvement of RFI. The most relevant indirect criteria are those integrating several experimental periods. Indeed, integrating several experimental periods and assigning to them weighting coefficients increase the degree of prediction from 0.07 to $0.20 \%$ for the feed deprivation periods, from 21 to $53 \%$ for the first period of feed deprivation/re-feeding, and from 22 to $44 \%$ for the second period. In addition, the combination of all the experimental periods leads to a marked increase in the percentage of RFI variance explained by the indirect criteria, which then reached 59\%. This highlights the interest in using composite criteria that allow combining both performances exhibited during feed deprivation and compensatory growth periods. Since, only performances during feed deprivation or re-feeding periods did not correlate with RFI, we could not verify the hypothesis that weight loss during feed deprivation and weight gain during re-feeding reflect variations in maintenance requirements and metabolic efficiency. Nevertheless, we confirm that, when combining feed deprivation and compensatory growth periods, they constitute a relevant indicator of RFI variations. However, even when all the $G$ are integrated, 
$40 \%$ of the RFI variation remains unexplained. It may be necessary to include additional indirect criteria in a breeding program to improve the percentage of RFI variation that can be predicted. Such additional criteria could include body lipid percentage as previously proposed [34].

The significant genetic correlation between the two periods of feed deprivation and the two periods of re-feeding shows that fish responses to feed deprivation and re-feeding are stable through time. Nevertheless, the first period of feed deprivation/re-feeding correlates better with RFI than the second. The differing level of response between the two periods may be the consequence of rapid fish adaptation to a repeated cycle of feed deprivation and re-feeding $[1,3,42]$, with a modulation of their physiological responses. Finally, we have demonstrated that the extent of phenotypic variation of weight loss during feed deprivation and compensatory growth explained by genetic variations is significantly different from 0 , confirming that, when used in combination, they are pertinent indirect criteria for selection.

We have shown that genetic variability exists for RFI in rainbow trout, confirming that genetic improvement is possible for this trait. Moreover, this variability is significantly correlated with traits integrating fish performances during feed deprivation and re-feeding. This is the first time that a correlation between RFI and traits easy to record has been reported. These traits provide ways of studying the origin of RFI differences and are excellent candidates for future selective breeding programs on RFI based on indirect criteria.

\section{ACKNOWLEDGEMENTS}

Authors thank two anonymous referees for their constructive comments on an earlier version of this manuscript. Authors are also grateful to Laurent Espinat and Nicolas Collanges for the daily care of the fish and sampling, Marc Vandeputte for his great help in data analyses, Sandrine Le Guillou for selection and management of the clone breeders, Amandine Launay for verifying the homozygous status of each breeder, and Marie Aurenche for her help during the planning of the experimental protocol.

\section{REFERENCES}

[1] Ali M., Wootton R.J., Capacity for growth compensation in juvenile threespined sticklebacks experiencing cycles of food deprivation, J. Fish Biol. 58 (2001) 1531-1544.

[2] Becker W.A., Manual of procedures in quantitative genetics, Pullmann, Washington, 1967. 
[3] Blake R.W., Inglis S.D., Chan K.H.S., Growth, carcass composition and plasma growth hormone levels in cyclically fed rainbow trout, J. Fish Biol. 69 (2006) 807-817.

[4] Bordas A., Tixier-Boichard M., Mérat P., Direct and correlated responses to divergent selection for residual food-intake in rhode-island red laying hens, $\mathrm{Br}$. Poult. Sci. 33 (1992) 741-754.

[5] Boujard T., Cuvier A., Geurden I., Labbe L., Mambrini M., Selection for growth and feeding hierarchy in brown trout, Appl. Anim. Behav. Sci. 99 (2006) 344-356.

[6] Chevassus B., Quillet E., Krieg F., Hollebecq M.G., Mambrini M., Labbe A.F.L., Hiseux J.P., Vandeputte M., Enhanced individual selection for selecting fast growing fish: the "PROSPER" method, with application on brown trout (Salmo trutta fario), Genet. Sel. Evol. 36 (2004) 643-661.

[7] Cho C.Y., Feeding systems for rainbow-trout and other salmonids with reference to current estimates of energy and protein-requirements, Aquaculture 100 (1992) 107-123.

[8] Cho C.Y., Bureau D.P., Determination of the energy requirements of fish with particular reference to salmonids, J. Appl. Ichthyol. 11 (1995) 141-163.

[9] Crews D.H., Genetics of feed evaluation and national cattle evaluation: a review, Genet. Mol. Res. 4 (2005) 152-165.

[10] Diter A., Quillet E., Chourrout D., Suppression of first egg mitosis induced by heat shocks in the rainbow-trout, J. Fish Biol. 42 (1993) 777-786.

[11] Gilmour A.R., Gogel B.J., Cullis B.R., Welham S.J., Thompson R., ASReml user guide release 1.0, 2002.

[12] Gjedrem T., Developments in fish breeding and genetics, Acta Agr. Scand. A Anim. Sci. (1998) 19-26.

[13] Gunsett F.C., Problems associated with selection for traits defined as a ratio of two component traits, in: Proceedings of the 3rd World Congress of Genetics Applied to Livestock Production, 1986, Vol. 11, Lincoln, NE, USA, pp. 437-442.

[14] Helland S.J., GrisdaleHelland B., Nerland S., A simple method for the measurement of daily feed intake of groups of fish in tanks, Aquaculture 139 (1996) 157-163.

[15] Henryon M., Jokumsen A., Berg P., Lund I., Pedersen P.B., Olesen N.J., Slierendrecht W.J., Genetic variation for growth rate, feed conversion efficiency, and disease resistance exists within a farmed population of rainbow trout, Aquaculture 209 (2002) 59-76.

[16] Herd R., Oddy V., Richardson E., Biological basis for variation in residual feed intake in beef cattle. 1. Review of potential mechanisms, Aust. J. Exp. Agr. (2004) 44.

[17] Hoque M.A., Suzuki K., Kadowaki H., Shibata T., Oikawa T., Genetic parameters for feed efficiency traits and their relationships with growth and carcass traits in Duroc pigs, J. Anim. Breed. Genet. 124 (2007) 108-116. 
[18] Jobling M., Techniques for measuring feed intake, in: Coves D., Damsgard B., Kristiansen H.R., Koskela J., Petursdottir T.E., Kadri S., Gudmundsson O. (Eds.), Food intake in fish, Oxford, 2001, pp. 49-96.

[19] Jobling M., Jorgensen E.H., Siikavuopio S.I., The influence of previous feeding regime on the compensatory growth-response of maturing and immature Arctic Charr, Salvelinus-Alpinus, J. Fish Biol. 43 (1993) 409-419.

[20] Kause A., Tobin D., Dobly A., Houlihan D., Martin S., Mantysaari E.A., Ritola O., Ruohonen K., Recording strategies and selection potential of feed intake measured using the X-ray method in rainbow trout, Genet. Sel. Evol. 38 (2006) 389-409.

[21] Kause A., Tobin D., Houlihan D.F., Martin S.A.M., Mantysaari E.A., Ritola O., Ruohonen K., Feed efficiency of rainbow trout can be improved through selection: different genetic potential on alternative diets, J. Anim. Sci. 84 (2006) 807-817.

[22] Kinghorn B., Genetic-variation in food conversion efficiency growth in rainbow-trout, Aquaculture 32 (1983) 141-155.

[23] Kolstad K., Grisdale-Helland B., Gjerde B., Family differences in feed efficiency in Atlantic salmon (Salmo salar), Aquaculture 241 (2004) 169-177.

[24] Komen H., Thorgaard G.H., Androgenesis, gynogenesis and the production of clones in fishes: a review, Aquaculture 269 (2007) 150-173.

[25] Lupatsch I., Kissil G.W., Sklan D., Comparison of energy and protein efficiency among three fish species gilthead sea bream (Sparus aurata), European sea bass (Dicentrarchus labrax) and white grouper (Epinephelus aeneus): energy expenditure for protein and lipid deposition, Aquaculture 225 (2003) 175-189.

[26] Mambrini M., Sanchez M.P., Chevassus B., Labbe L., Quillet E., Boujard T., Selection for growth increases feed intake and affects feeding behavior of brown trout, Livest. Prod. Sci. 88 (2004) 85-98.

[27] Mambrini M., Medale F., Sanchez M.P., Recalde B., Chevassus B., Labbe L., Quillet E., Boujard T., Selection for growth in brown trout increases feed intake capacity without affecting maintenance and growth requirements, J. Anim. Sci. 82 (2004) 2865-2875.

[28] McCarthy I.D., Houlihan D.F., Carter C.G., Moutou K., Variation in individual food-consumption rates of fish and its implications for the study of fish nutrition and physiology, Proc. Nut. Soc. 52 (1993) 427-436.

[29] McCarthy I.D., Houlihan D.F., Carter C.G., Individual variation in proteinturnover and growth efficiency in rainbow-trout, Oncorhynchus-mykiss (Walbaum), Proc. R. Soc. B Bio. 257 (1994) 141-147.

[30] Nikki J., Pirhonen J., Jobling M., Karjalainen J., Compensatory growth in juvenile rainbow trout, Oncorhynchus mykiss (Walbaum), held individually, Aquaculture 235 (2004) 285-296.

[31] Pitchford W.S., Genetic improvement of feed efficiency of beef cattle: what lessons can be learnt from other species?, Aust. J. Exp. Agr. 44 (2004) 371-382. 
[32] Quillet E., Dorson M., Le Guillou S., Benmansour A., Boudinot P., Wide range of susceptibility to rhabdoviruses in homozygous clones of rainbow trout, Fish Shellfish Immunol. 22 (2007) 510-519.

[33] Quinton C.D., Breeding salmonids for feed efficiency in current fishmeal and future plant-based diet environments, Genet. Sel. Evol. 39 (2007) 431-446.

[34] Quinton C.D., Kause A., Ruohonen K., Koskela J., Genetic relationships of body composition and feed utilization traits in European whitefish (Coregonus lavaretus L.) and implications for selective breeding in fishmeal- and soybean meal-based diet environments, J. Anim. Sci. 85 (2007) 3198-3208.

[35] Silverstein J.T., Relationships among feed intake, feed efficiency, and growth in juvenile rainbow trout, N. Am. J. Aquacult. 68 (2006) 168-175.

[36] Silverstein J.T., Hostuttler M., Blemings K.P., Strain differences in feed efficiency measured as residual feed intake in individually reared rainbow trout, Oncorhynchus mykiss (Walbaum), Aquac. Res. 36 (2005) 704-711.

[37] Snowder G.D., van Vleck L.D., Estimates of genetic parameters and selection strategies to improve the economic efficiency of postweaning growth in lambs, J. Anim. Sci. 81 (2003) 2704-2713.

[38] Thodesen J., Grisdale-Helland B., Helland S.J., Gjerde B., Feed intake, growth and feed utilization of offspring from wild and selected Atlantic salmon (Salmo salar), Aquaculture 180 (1999) 237-246.

[39] Thodesen J., Gjerde B., Grisdale-Helland B., Storebakken T., Genetic variation in feed intake, growth and feed utilization in Atlantic salmon (Salmo salar), Aquaculture 194 (2001) 273-281.

[40] Thodesen J., Storebakken T., Shearer K.D., Rye M., Bjerkeng B., Gjerde B., Genetic variation in mineral absorption of large Atlantic salmon (Salmo salar) reared in seawater, Aquaculture 194 (2001) 263-271.

[41] Tixier-Boichard M., Boichard D., Groeneveld E., Bordas A., Restricted maximum-likelihood-estimates of genetic-parameters of adult male and female rhode-island red chickens divergently selected for residual feed consumption, Poultry. Sci. 74 (1995) 1245-1252.

[42] Wu L., Xie S., Cui Y., Wootton R.J., Effect of cycles of feed deprivation on growth and food consumption of immature three-spined sticklebacks and European minnows, J. Fish Biol. 62 (2003) 184-194. 